\title{
LA APORTACIÓN DE FRANCISCO SUÁREZ AL CONCEPTO DE PROPIEDAD DE LA TRADICIÓN ESCOLÁSTICA
}

\author{
NIEVES SAN EMETERIO \\ Universidad Rey Juan Carlos
}

\begin{abstract}
RESUMEN: En este artículo se hace una valoración de la doctrina de la propiedad de Francisco Suárez en relación a la tradición escolástica a la que pertenece. Encontramos aspectos muy similares a la de otros autores escolásticos como la defensa consecuencialista de la propiedad o los límites a la exclusividad en caso de extrema necesidad, pero también existen aspectos muy novedosos como la justificación de la apropiación por el trabajo en el estado de naturaleza. Su doctrina también se aleja de la tradición tomista cuando analiza la categoría de la apropiación como un derecho permisivo y preceptivo al mismo tiempo, un atributo que confiere la exclusividad al propietario y dota a sus ideas de una gran modernidad
\end{abstract}

PALABRAS CLAVE: Francisco Suárez; propiedad.

\section{The contribution of Francisco Suárez to the concept of property of scholastic tradition}

\begin{abstract}
In this paper, an assessment is made of the doctrine of the property of Francisco Suárez in relation to scholastic tradition to which he belongs. We find aspects very similar to other scholastic authors such as the consequentialist defence of property or the limits to exclusivity in case of extreme necessity but there are also very novel aspects such as the justification of appropriation for labour in the state of nature. His doctrine also moves away from the Thomistic tradition when he analyses the category of appropriation as a permissive and prescriptive right at the same time, an attribute that confers exclusivity on the owner and endows his ideas with a great modernity.
\end{abstract}

KEY WORDS. Francisco Suárez; Property.

\section{INTRODUCCIÓN}

En el año 2017 se cumplieron los 400 años de la muerte de Francisco Suárez (1548-1617) y con motivo de este centenario se está recuperando su legado en los muy diversos ámbitos científicos: la teología, la metafísica o la teoría política. Nos sumamos a este reconocimiento en este caso desde el prisma de la economía en un tema que se ha incorporado al análisis económico ortodoxo desde hace poco más de cinco décadas. A la luz del análisis económico actual pretendemos extraer de la obra de Suárez su doctrina de la propiedad. Estudiaremos la defensa consecuencialista de la propiedad privada y los límites a la exclusividad de los derechos en relación a la tradición de pensamiento escolástico de su época. También valoraremos la modernidad de su pensamiento en esta materia como precursor de la teoría lockeana de la apropiación.

Antes de nada debemos realizar la advertencia de que la visión que vamos a dar del concepto de propiedad aquí es eminentemente económica y, por tanto, subrayaremos determinados aspectos que resultan especialmente importantes desde esta disciplina como los límites a la exclusividad de este derecho o la 
defensa de la propiedad privada por argumentos utilitaristas. Somos conscientes de que este acercamiento nos aleja de la propia visión escolástica, donde el orden económico escolástico está subordinado a las exigencias de la moral y por tanto sometido a las reglas de justicia en sus diversas manifestaciones: tanto de justicia conmutativa como de justicia distributiva (Sierra Bravo, 1975:112). Sin embargo, consideramos que el acercamiento desde la perspectiva económica puede enriquecer y revalorizar el legado de Suárez.

El trabajo se desarrolla del siguiente modo. En primer lugar, intentaremos hacer una pequeña definición de conceptos sobre propiedad, propiedad privada y dominio en la escolástica en general y en Suárez en particular. En segundo lugar, abordaremos la defensa de la propiedad privada frente a la común, un aspecto especialmente relevante para el análisis económico. En tercer lugar, hablaremos de la jerarquía jurídica de la propiedad contextualizando las aportaciones de Suárez en el pensamiento escolástico. En cuarto lugar, veremos la justificación moral de la apropiación, quizá el aspecto más original e influyente de la obra de Suárez. Seguiremos con los límites a la exclusividad de los bienes para terminar con un breve apartado sobre la relación entre el poder público y la propiedad. La reconstrucción de la teoría de la propiedad en Suárez la realizaremos a partir de los fragmentos dedicados a este tema dispersos en toda su obra porque en ninguno de sus libros hay un tratamiento sistemático de la propiedad. No obstante, la mayoría de sus ideas sobre la propiedad las podemos encontrar en De Legibus ac Deo legistatore [1612], en De opere sex dierum [1621] y en De fide, spe et Charitate [1621]

\section{Definición De CONCEPtos}

Antes de adentrarnos en el estudio de la doctrina de la propiedad de Francisco Suárez hemos de realizar una definición de conceptos. El primero de ellos tiene que ver con la definición de propiedad privada. Generalmente el pensamiento escolástico no utiliza el término de "privada», sino simplemente propiedad o posesión. En realidad detrás de esta omisión está la idea que la propiedad privada contradice el destino universal de los bienes y, por tanto, no se puede hablar de exclusividad perfecta en el uso de los bienes. Por tanto, como sucede en Santo Tomás, la posesión tiene que ver más con la facultad de gestión y administración más que un derecho al uso exclusivo de un bien.

Como señala Ferreiro López (1948), no hay criterio fijo en la teología suareziana en el uso de las voces «dominio» y "propiedad». Hay veces que las emplea como sinónimas y otras veces atribuyendo a una el significado de la

1 Utilizaremos la edición de 1967 De Legibus, del Instituto de Estudios Políticos, el resto de referencias están tomadas de su Opera Omnia (1856). 
otra $^{2}$. En general, el concepto de dominio es un concepto amplio y se concibe como una potestad o superioridad de un ser sobre otro. Dentro de las clases de dominio cabe un dominio de jurisdicción y otro de propiedad. El primero se denomina también gobierno que confiere la potestad de gobernar y dirigir a los súbditos. El «dominio de propiedad» confiere la «facultad al dueño para usar del objeto de su dominio con todos los usos lícitos y convenientes a su naturaleza y extraer sus utilidades para emplearlos en su propio provecho». Como es habitual en la escolástica, muy raras veces Suárez utiliza esta expresión de propiedad privada, prefiere hablar sobre «la división de los dominios». Una de estas raras ocasiones donde define la propiedad privada aparece en De virtute et Statu Religionis donde determina que la propiedad privada es «el derecho principal a disponer de alguna cosa en cualquier uso no prohibido por la ley» (L. VII, CV, n.4).

Lo anterior se puede resumir en las siguientes categorías:

1) Dominio, relación de superioridad y dependencia entre el hombre y los seres de la creación.

2) Dominio-propiedad: relación de superioridad concretada en la facultad moral de utilizar los bienes creados para el provecho del hombre.

3) Propiedad privada: organización práctica de esta facultad moral en virtud de la cual los hombres utilizan los bienes apropiándoselos de una manera propia, estable y exclusiva (Ferreiro López, 1948: 464).

Pero existe aún otra jerarquía adicional en el dominio: el dominio supremo de Dios; el dominio de Excelencia de Jesucristo; el dominio alto del Estado y, por último, el dominio pleno y perfecto del propietario. De esta clasificación, nos interesa el llamado «dominio alto» del Estado, un dominio que no es simple jurisdicción, va más allá porque da cabida a la posibilidad de expropiación de los bienes de los súbditos. El jefe del Estado es el supremo administrador y distribuidor de los bienes del país, no por razón de su potestad jurisdiccional, sino por razón del especial dominio de propiedad que tiene sobre ellos; por eso puede usarlos, quitarlos, transferirlos, etc. (Suárez, 1967, L. I. C. XVII, n. 11). Esta potestad que atribuye al Estado sorprende cuando para muchos la doctrina de la propiedad de Suárez anticipa las ideas de Locke sobre la propiedad privada, precisamente una teoría ésta que fundamenta los límites del poder político. Para huir de esta conclusión, Ferreiro López se afana en buscar pasajes en la obra de Suárez que aclaren este «dominio alto» y lo encuentra en los Opuscula Theologica (Suárez, 1856, VI, secc. 1, n.12), donde Suárez aplica este concepto a la capacidad del Estado de disponer de los bienes cuando fuese necesario al bien común de la sociedad (Ferreiro López, 1948: 480). Más adelante, veremos la relación entre propiedad y Estado con mayor detalle.

2 El artículo de Antonio Ferreiro López de 1948 es referencia habitual en el estudio de la propiedad de Suárez. En su primera parte realiza una virtuosa labor de aclaración de conceptos que resumimos aquí. 


\section{DEFENSA DE LA PROPIEDAD PRIVADA FRENTE A LA COMÚN}

Para comprender la doctrina de la propiedad de Suárez y valorar los aspectos más novedosos es necesario contextualizar sus aportaciones en la tradición escolástica. Comencemos por analizar la defensa de la propiedad privada frente a la común. El aspecto más relevante en este sentido es el proceso de rehabilitación de la propiedad privada frente a la común que había comenzado en Santo Tomás. El uso común de los bienes estaba avalado en los textos sagrados. Dios había concedido los bienes de la tierra para uso común de los hombres y la propiedad privada era considerada por la Patrística como un mal menor al que ha de acostumbrarse el hombre en el estado de naturaleza caída. Sin embargo, la controversia sobre la pobreza apostólica durante los siglos XIII y XIV por parte de la orden franciscana iba a impulsar un proceso de rehabilitación de la propiedad privada frente a la común porque decían poder revivir ese pseudo-estado natural mediante la práctica de la pobreza ${ }^{3}$. Santo Tomás retomó las ideas aristotélicas en este aspecto. Los argumentos aristotélicos-tomistas se pueden clasificar en tres tipos: económicos, la propiedad privada frente a la común posibilita un mejor aprovechamiento de los recursos; sociales, la propiedad privada elimina conflictos y contribuye a la paz social, y morales pues la propiedad privada contribuye a que el hombre tome una actitud más virtuosa que si los bienes fueran utilizados en común.

Prácticamente este tipo de argumentos se repiten en el pensamiento escolástico posterior y la Escuela española. Domingo de Soto es uno de los autores que desarrolla mejor esta idea al analizar los inconvenientes de la posesión en común. Si los terrenos fueran propios y los frutos comunes, dice Soto,

das ocasión a discordias, porque en este caso los trabajos serían desiguales, ya que quien tiene más terreno, tiene más que trabajar, y los frutos en cambio, se repartirían del mismo modo a todos según la necesidad de cada uno, y nadie llevaría con igualdad de ánimo que no recibiera tanto cuanto su trabajo hubiera producido (Soto, 1968: Libro IV, q.3, a.1, 296-7).

Si los terrenos fuesen comunes y no así los frutos, también surgirían problemas pues,

los hombres tomarían de aquí motivo para la desidia y flojedad, porque es indecible el amor ardiente que se tiene por las cosas propias y lo desidioso y flojo que es para las comunes. (Ibíd.)

Lo mismo sucedería si fueran comunes al mismo tiempo terrenos y frutos, pues «uno arrebataría cuantos frutos le fuera posible, cosa que en esta ocasión intentarían todos en provecho propio, dada la sed de riqueza de los hombres». Pero, es más, con la propiedad privada disminuyen los conflictos pues no puede "por menos de intranquilizar gravemente a la sociedad si el dominio no estuviera dividido" y hace al hombre actuar moralmente ya que

3 Para un análisis exhaustivo sobre el tema San Emeterio, 2005, cap. I. 
si hubiera comunidad de bienes desaparecería la virtud de la liberalidad; lo cual no es pequeño esplendor para la nación (...). Y de esta manera desaparecería la virtud de la hospitalidad, ni se atendería a los peregrinos, ni se socorrería a los necesitados; y como consecuencia desaparecería la virtud del agradecimiento por los beneficios recibidos (Ibid.)

Se puede decir que los argumentos de Domingo de Soto a favor de la propiedad en poco se alejan de los apuntados antes por Santo Tomás o por el mismo Aristóteles y que, salvo excepciones, son compartidos por el resto de los doctores escolásticos; a saber: que los bienes que se tienen en propiedad privada se usan mejor que aquellos que se tienen en común. Además de esta justificación económica existe una segunda justificación, esta vez social, pues la división y reparto de los bienes proporciona un mayor orden a la sociedad; y una última moral, que facilita el comportamiento virtuoso de los hombres.

Suárez continúa con esta tradición y señala:

la división de cosas [en cuanto al dominio de tierras, de frutos, de animales y de otras cosas temporales] es necesaria ahora, bien para evitar las pendencias entre los hombres y conservar la paz, o bien para el sustento de los hombres, porque si los bienes fuesen comunes, los hombres descuidarían el guardarlos y el cultivarlos; pero estas dos razones no habrían tenido vigencia en el estado de inocencia. (Suárez, 1856, De opere sex dierum, V, VIII, 18).

Como vemos, Suárez hace alusión a la justificación eficientista de la propiedad privada frente a la común, además de la justificación social que aparecía en Aristóteles y Santo Tomás. Más allá de esta explicación, que replica de la tradición escolástica, no aparece otra contribución suareziana digna de mención en este campo. Otro tanto se puede decir de la categoría jurídica que confiere a la propiedad privada.

\section{Categoría de la PROPIEDAD}

El origen de la jerarquía jurídica de la propiedad en el pensamiento escolástico procede del Decreto de Graciano y se puede resumir del siguiente modo:

$1^{\circ}$ Que la comunidad de bienes es de derecho natural, mientras que la división de los mismos es de derecho positivo.

$2^{\circ}$ Que el fundamento de la posesión privada es la iniquidad o el pecado, es decir, la malicia humana, correspondiendo, por tanto, al estado de naturaleza caída o corrompida, mientras que la comunidad de bienes pertenece al estado original de naturaleza caída (Sierra Bravo, 1975: 115).

Esta separación estricta entre la propiedad común en el estadio anterior al pecado original, por una parte, y la propiedad privada en el estado de naturaleza caída, por otro, tuvo una importante revisión con Santo Tomás de Aquino. Como hemos dicho arriba, la aspiración de los franciscanos de emular 
la posesión común de los apóstoles hizo necesario, no sólo revalorizar los efectos beneficiosos de la propiedad privada frente a la común, sino también elevar la categoría jurídica de esta porque el mero derecho civil era un recurso menor y mutable a voluntad de los Estados.

Santo Tomás fue uno de los primeros autores en realizar un acercamiento de la jerarquía jurídica de la propiedad hacia posiciones más elevadas que la correspondiente a un simple derecho positivo. Según él, no hay una incompatibilidad total entre la comunidad de bienes y la propiedad porque «la propiedad de las posesiones no es contraria a derecho natural, sino que se la sobreañade por conclusión de la razón humana» (Tomás de Aquino, 1963: vol. III Secunda Secundae, q.66 a.2, 426). La segunda escolástica de los siglos XVI y XVII se iba a caracterizar por seguir la senda abierta por el Aquinate de rehabilitar a la propiedad a un estatus superior. Así es normal adscribir la propiedad al derecho de gentes (un derecho intermedio entre el natural y el positivo común entre todas las naciones). Tal vez fue Domingo de Soto el primer autor que aplicó el derecho de gentes con detalle a la división de los dominios. Para él, es la conveniencia la que hace surgir el derecho de gentes y la propiedad privada y su utilidad se extrae directamente del derecho natural. En consecuencia, para establecer el derecho de gentes «no se precisa la reunión de todos los hombres en un determinado lugar» a diferencia del derecho civil, «pues la misma razón les enseña lo mismo a todos», y es por ello que el «derecho de gentes es común a todos los pueblos» (Soto,1968: Libro III, q.1, a. 3, 197).

Francisco Suárez realiza un análisis similar. En su obra De legibus ac Deo legislatore,

asimismo la división de los campos y tierras, de los campos, emplazamientos y términos comunales se dice que es de derecho de gentes, división que supone la institución de las sociedades humanas; supuesta ésta, en virtud de sola la razón natural, todas esas cosas son lícitas, aunque no sean sencillamente necesarias (Suárez,1967: L. 2, cap. 18, nº 13, 185).

Además, Suárez explícitamente clasifica a ese derecho de gentes como aquel «que se distingue del derecho natural primario a manera de derecho natural secundario» (Ibíd.), todo lo cual subraya el carácter del derecho de gentes como derecho intermedio, cercano al natural.

No obstante, según el estudio de Ferreiro López, Suárez matiza esa conveniencia de la propiedad privada en todos y cada uno de los hombres. Según Suárez en su obra De Virtute et Statu Religionis (L. VIII, C.8, n. 22), la propiedad privada no se introdujo de modo imperativo para todos los hombres en particular y, por ello, es posible el voto de pobreza y la posesión en común de los religiosos (Ferreiro López, 1948: 476). En este aspecto, la jerarquía jurídica de la propiedad compatibilizaba el ideal de pobreza al que aspiraban los franciscanos con la posesión privada de otras órdenes religiosas. En ambos casos, el derecho de gentes daba cabida a ambos escenarios.

Como acabamos de ver, Suárez, como otros escolásticos españoles, utiliza esa jerarquía intermedia entre el derecho natural y el civil en la creencia 
que el derecho positivo era un débil refugio a sus teorías sobre la propiedad porque, por encima de él, prevalecía un derecho natural por el cual las cosas permanecían comunes a todos los hombres. No obstante, donde la aportación de Francisco Suárez es más novedosa es cuando contempla la posibilidad de la apropiación en el estado de naturaleza como veremos a continuación.

\section{JUSTIFICACIÓN DE LA APROPIACIÓN}

Dentro de este epígrafe sobre las teorías escolásticas de la apropiación es necesario analizar las ideas de aquellos teólogos que mantuvieron una teoría basada en el trabajo y que anticipan la teoría de Locke. En realidad son casos excepcionales puesto que únicamente Francisco Suárez o, más tarde, Juan de Lugo hacen explícita su alusión al trabajo como criterio ético para la aprehensión de los bienes ${ }^{4}$.

La justificación más utilizada por la escolástica para la apropiación de los bienes es la ocupatio rei nullius, es decir, la ocupación de lo que no es de nadie. Sin embargo, Suárez incorpora al trabajo como criterio ético de apropiación en un escenario poco habitual: en el estado de naturaleza.

Una diferencia entre las ideas de Santo Tomás presentes en el iusnaturalismo cristiano y las de John Locke, del iusnaturalismo racionalista, es que mientras el primero se limitaba a decir que la división de propiedades no era contraria al derecho natural, la gran aportación del segundo era precisamente incluir la propiedad privada como un derecho natural y, por tanto, presente en el estado previo a la creación de la sociedad civil. Esta misma idea aparece en la obra de Suárez De opere sex dierum y constituye, a nuestro entender, la más importante aportación de Suárez a la doctrina de la propiedad.

Después de distinguir entre bienes muebles e inmuebles, añade que «los muebles están más sujetos a división, pues por el mismo hecho de ser ocupados o tomados se hacen del que los ocupa». En este aspecto no parece existir ninguna diferencia sustancial con otros autores escolásticos y que fundamentan la apropiación en la ocupación. Sin embargo, seguidamente agrega:

Este derecho parece que habría sido necesario también en el estado de inocencia. Porque parece que quien recogiera frutos del árbol para comer, por ello mismo debía adquirir un derecho peculiar sobre ellos, para poder usar libremente los mismos y para que no pudiera serle arrebatados contra su voluntad poseedora sin justicia (Suárez, 1856, T. III, L. 5, cap. 7, n 17, 418).

\footnotetext{
4 El profesor Baciero Ruiz ha investigado profusamente la influencia que pudo tener Suárez en la obra de Locke. Aporta un significativo número de evidencias sobre la posibilidad de que conociera al autor español: existía una traducción completa al inglés de la obra de Suárez en época de Locke; el libro de Robert Filmer, Patriarca, que dio origen al Primer Tratado sobre el Gobierno Civil de Locke, hacía alusión a las doctrinas del De Legibus de Suárez. También Locke pudo tener conocimiento de la obra de Suárez a través de la obra de Nathanael Culverwell (1618-1651) (BACIERo Ruiz, 2012: 408-412).
} 
Esto es, el derecho de propiedad de los bienes muebles también existiría en ese estado inicial del hombre, antes del pecado original. Pero, es más, en este caso, es el trabajo de los individuos el que otorga el derecho de uso y exclusión, es decir, el derecho de propiedad sobre tales bienes. Sin duda las semejanzas con el pensamiento de Locke son patentes. Ambos utilizan incluso un mismo ejemplo,

Ciertamente, quien se ha alimentado de las bellotas que él mismo ha recogido de debajo de una encina, o de las manzanas que ha cosechado de los árboles del bosque, puede decirse que se ha apropiado de ellas. Nadie podrá negar que ese alimento es suyo. (Locke, 1990, c.5, 57).

La alusión a la apropiación de los frutos recolectados indica que ambos consideran que es el trabajo aplicado a esta tarea el que da origen de la propiedad y no la ocupación de los bienes comunes. Además, como ya se ha dicho, para ambos autores esta apropiación se efectúa en el estado de naturaleza. No obstante, Suárez matiza bastante su postura respecto del resto de los bienes y seguidamente añade:

Sin embargo en los bienes inmuebles no sería necesaria semejante división y a ellos se refieren principalmente dichos autores. Pero se ha de tener en cuenta, además, que habrían podido los hombres en este estado trabajar la tierra y sembrar quizá alguna parte de ella. (Suárez, 1856, T. III, L. 5, cap. $\left.7, \mathrm{n}^{\circ} 17,418\right)$.

Es decir, no está claro que la división de los bienes inmuebles se pudiera realizar en el estado de naturaleza, aunque admite que en él los hombres podrían haber trabajado la tierra. El trabajo no sería en este caso el fundamento de la propiedad sino una mera costumbre que «no repugna a aquel estado». (Ibíd.)

En este sentido, cabe perfectamente la interpretación de Baciero Ruiz, para quien el concepto de derecho en Suárez es un concepto subjetivo, una facultad de índole moral que se transmite hacia el objeto sobre el cual se ha aplicado ese trabajo, "pues tener derecho a algo significa no sólo tener un poder efectivo sobre ello, sino estar moralmente legitimado para ejercerlo» (Baciero Ruiz, 2012: 394-397). Las cercanías con los postulados de Locke son claros en este mismo sentido.

Aunque la teoría de Suárez sobre la apropiación tiene muchos parecidos a la lockeana de la propiedad basada en el trabajo, con todo, comparte con la tradición escolástica el vínculo con la doctrina de la ocupación. Además, esta idea es utilizada por Suárez para demostrar que no es posible la separación de un derecho concesivo con otro prohibitivo. Su razonamiento es el siguiente:

El primer ejemplo es la ocupación de emplazamiento, la cual es tan lícita a cualquiera por derecho de gentes o — más bien— natural, que ninguno puede justamente impedir a otro que ocupe un emplazamiento que no ha sido antes ocupado por otro; así aquella concesión lleva consigo este precepto (Suárez, 1967: L. 2, c. XVIII, nº 4, 185). 
Sin embargo, lo importante aquí no es la adscripción a la teoría de la ocupación de la cosa común. Lo realmente trascendente es que este razonamiento es utilizado como ejemplo para dilucidar las características del derecho: un derecho - natural o de gentes_ que es al mismo tiempo permisivo y prohibitivo. Quizá el siguiente ejemplo utilizado por Suárez evidencia más claramente esta idea.

El segundo ejemplo es la edificación, y el tercero es el cercamiento, para los cuales vale la misma razón, pues es contradictorio el que uno tenga facultad libre para edificar o para cercar la tierra o la posesión que ha ocupado, y que otros puedan impedirle o perturbarle justamente en el ejercicio de esa facultad; luego es necesaria la unión de ambos derechos concesivo y preceptivo. (Ibíd.)

Según esta cita no se puede concebir un derecho que otorgue el disfrute de un bien sin su correspondiente derecho de prohibición para el resto. La aplicación a los temas de la propiedad —apropiación y delimitación- no es casual, porque precisamente en estas materias la separación de ambos derechos da lugar a ciertas contradicciones. Contradicciones que aparecían en la doctrina de Santo Tomás y que ahora intentaremos aclarar.

En la teoría de Santo Tomás sobre el origen de la propiedad, extraída de la Summa Theologica, se habla de la separación entre el uso común y dominio privado. Es decir, alguien que se apodera de un recurso no puede impedir que el resto pueda acceder también a él; del mismo modo que aquél que entra en un espectáculo no puede impedir la entrada a otros (Tomás de Aquino, 1963: q.66, a.2, ad.2, 426). La propiedad adquirida de este modo no puede considerarse como privada pues no se puede cumplir la exclusividad. Obsérvese que en la cita de Suárez lo que dice, aunque parecido, es radicalmente distinto. Para Suárez una vez ocupado el emplazamiento no se puede impedir que otra persona tome «lo que no ha sido antes ocupado», por el contrario, para Santo Tomás, quien se apodera primero de una cosa peca si priva a los demás de su uso.

Suárez pone en jaque la idea de Tomás de Aquino. En los párrafos que acabamos de citar se considera inseparable el derecho a usar un bien - edificando o cercando un terreno, como él expone- con el derecho a excluir al resto de su disfrute: porque la «concesión lleva consigo este precepto». En este caso el derecho de propiedad que se adquiere se puede considerar realmente privado puesto que va incluida su exclusividad. Suárez estaría de esta forma rebatiendo las características del derecho de propiedad en Santo Tomás: un derecho concesivo pero no prohibitivo.

Por consiguiente, la teoría de Suárez constituye una excepción en la doctrina de la apropiación de la escolástica, no sólo debido a su teoría sobre el origen de la propiedad basado en el trabajo, sino también a que su concepto derecho - permisivo y perceptivo al mismo tiempo — se asemeja a la noción moderna de la propiedad privada. 


\section{LÍMITES A LA PROPIEDAD PRIVADA}

Arriba, cuando definíamos los conceptos de propiedad privada en la terminología de Suárez, apuntábamos la definición de que la propiedad privada es aquella potestad de usar los bienes en todos los usos que no prohibiera la ley. Esta definición es muy similar a la actual porque nuestra propiedad está afectada por la ley en todos sus usos. Más allá de los límites que imponen las leyes positivas a la propiedad, aquí estudiaremos los límites morales que contemplaron los doctores escolásticos; unos límites que no estaban codificados en ningún ordenamiento jurídico pero que restringían precisamente el uso exclusivo de los bienes. Este es el caso del supuesto de extrema necesidad. Aquí se unían dos cuestiones: una limitación a la propiedad motivada por razones morales y un ejemplo de la aplicación de la jerarquía jurídica en torno a los derechos.

El planteamiento es el siguiente: cuando alguien se encontraba en una situación de peligro de muerte por no tener lo necesario para la subsistencia, entonces renacía el derecho natural y por consiguiente el individuo podía tomar lo ajeno para aliviarse con o sin el consentimiento del propietario. Veamos algunos ejemplos. Santo Tomás declara:

si la necesidad es tan evidente y tan urgente que resulte manifiesta la premura de socorrer la inminente necesidad con aquello que se tenga, como cuando amenaza peligro a la persona y no puede ser socorrida de otro modo, entonces puede cualquiera lícitamente satisfacer su necesidad con las cosas ajenas, sustrayéndolas, ya manifiesta, ya ocultamente. Y esto no tiene propiamente razón de hurto ni de rapiña (Tomás de Aquino, 1963: q.66, a.7, 430-31).

Además, la extrema necessitas legitima la expropiación, aunque ésta se haga ocultamente pues

el usar de la cosa ajena ocultamente sustraída no tiene razón de hurto propiamente hablando, puesto que por tal necesidad se hace suyo lo que uno sustrae para sustentar su propia vida. (Ibíd.)

Francisco Suárez, por su parte, incluye en el Tratado de las Leyes y de Dios Legislador el caso de «especial necesidad o causa justa» como ejemplo en el que se compatibiliza la división de la propiedades con el uso común por derecho natural (Suárez, 1967: Libro 2, c.14, n.17, 159). Pero es en su obra De fide, de spe, de charitate donde desarrolla detalladamente esta idea. Nuevamente se repiten los mismos razonamientos, pero esta vez el necesitado en extremo puede tomar para sí incluso bienes que también son necesarios para el prójimo. Y así:

quien está necesitado en modo extremo, tiene derecho natural de usar los bienes de otro, incluso de los que sean necesarios a éste según su estado, y puede tomarlos, sin que otro pueda prohibir sin injusticia. (Suárez, 1856: T. XII, trat. 3, disp. 7, sec. 4, 686).

Además, la obligación de socorrer al necesitado no se limita a la llegada de una necesidad extrema, Suárez admite tal obligación cuando se dé «cierta gravísima necesidad». Tampoco ha de estar en peligro la vida del necesitado, 
basta que exista "peligro extremo de infamia grave, o injuria similar y ésta es necesidad gravísima» (Ibíd.: 687). En este sentido, Suárez no se aleja de lo mantenido por Francisco de Vitoria o con Domingo de Soto, en Suárez los límites del caso de la extrema necesidad son bastante amplios.

Como en el resto de los doctores escolásticos, en Suárez existe una primacía de la vida, por consiguiente, cuando está en peligro la vida del individuo, el derecho de propiedad cede, porque revive ese derecho natural al uso común de todos los bienes de todo el orbe.

Unido al supuesto de extrema necesidad está la obligación de dar limosna de lo superfluo. Santo Tomás, apelando una vez más a la tradición aristotélica, mantiene la idea de que el destino de los bienes es la satisfacción de necesidades, por tanto, una vez cubiertas, los bienes superfluos deben pasar a los necesitados, independientemente de si su estado es de necesidad extrema o no. Así, señala, «los bienes superfluos que algunas personas poseen son debidos por derecho natural, ex jure naturali, al sostenimiento de los pobres» (Tomas de Aquino, 1963, q.66, 7).

Suárez conviene con Santo Tomás en lo principal, es decir, la obligación de dar limosna de lo superfluo «no sólo en extrema, sino también en grave necesidad» obliga este precepto bajo pecado mortal al propietario (Suárez, 1856: Tomo XII, trat. 3, disp. 7, sec. 4, 682-ss).

Sin embargo, más adelante define estrictamente el concepto de superfluo porque «se ha de tener en cuenta el estado del rico y su decencia íntegra». Es decir, dentro de lo necesario (no superfluo), estarían los bienes que atesora para el porvenir de los hijos y otras personas domésticas. Además, también considera bienes no superfluos los bienes que se destinen al ascenso social porque «sería necesario para la república». Y pone como ejemplos la edificación de templos y de colegios escolásticos. Las riquezas gastadas en estos casos también pertenecen a la piedad cristiana, apunta Suárez. Por último, admite que quien posee bienes superfluos no peca mortalmente si alguna vez los gasta en "usos vanos», siempre y cuando haga limosna de vez en cuando "aunque otras veces deje de hacerla en muchos casos» (Ibid.).

Como se puede apreciar, y es típico de la Segunda Escolástica, Suárez tiene una actitud mucho más laxa de lo que es necesario o superfluo. Como en el caso de las cuestiones sobre la usura, la doctrina escolástica hubo de adaptarse a los cambios en la realidad económica del momento «lo que obligó a los escolásticos a buscar nuevas fórmulas, muchas no muy consecuentes con los principios fundamentales, para adaptar hasta cierto punto la doctrina a las necesidades de la realidad económica» (Sierra Bravo, 1975: 195).

\section{RELACIÓN ENTRE EL PODER POLÍTICO Y LA PROPIEDAD}

En el primer apartado de este trabajo hacíamos alusión al concepto de «dominio alto», un derecho similar al de la propiedad que ostenta el soberano sobre los bienes de sus súbditos. En este apartado estudiaremos algunos casos 
concretos en donde el príncipe puede, alegando el bien común, ejercer este dominio. No obstante, consideramos que un estudio completo de la relación Estado y propiedad entra de lleno en las consideraciones de la teoría política de Suárez que desborda el objetivo de este estudio.

Francisco Suárez, como dijimos en el primer epígrafe, utiliza el argumento del «bien común» a la hora de justificar la acción del príncipe. Tampoco concreta esta actuación, pero sí señala que las leyes tributarias «inmediatamente miran el bien común», porque

por más que parezcan ceder en provecho del príncipe, sin embargo, para ser verdaderas leyes, deben mirar al bien común, ya que los tributos no se dan al rey si no es en cuanto persona de significación común y pública y para que use de ellos para el bien común. (Suárez, 1967: L. I, c.VII, nº 13, 42).

Es decir, la fiscalización pública está totalmente justificada pues las leyes tributarias, prácticamente por definición, procuran el bien común ${ }^{5}$. Además, aunque no hace alusión a las propiedades de los súbditos, admite que determinadas leyes pueden dañar a los particulares, sin embargo,

no se lo tiene tanto en cuenta, y por eso algunas veces se lo permite - por ejemplo, en la prescripción, que mira al bien común, o sea, a la paz, evitando las contiendas, etc. - y otras veces incluso se pretende - por ejemplo, en las leyes punitivas, las cuales son también necesarias para el bien común. (Ibíd., $\left.\mathrm{n}^{\circ} 15,43\right)$.

Por consiguiente, es lícito que el soberano afecte a los particulares si con ello logra mantener la paz y aplicar la justicia. Ambos objetivos pertenecen a la categoría de bien común. Sin embargo, las posibilidades de intervención no se limitan a estos dos casos. Siempre que la ley sea necesaria y posea una cierta utilidad fomentará el bien (Ibíd.) y, por lo tanto, será justa. En otra de sus obras citada arriba, De fide, de spe, de charitate, Suárez utiliza de nuevo el concepto de bien común en una curiosa mezcla de argumentos: apoya la injerencia del Estado sobre los bienes de sus súbditos aludiendo al caso de extrema necesidad, en este caso de la misma república:

Si el bien común o la república se halla en necesidad grave, están obligadas las personas privadas a subvenir a aquella necesidad incluso de lo necesario al estado. La razón es porque, en igualdad de circunstancias, el bien común ha de ser preferido al propio en los asuntos temporales. Además, (...) el hombre debe perder la vida, si fuera preciso, por la conservación de la vida de la república, luego de modo semejante está obligado a sufrir necesidad grave, para subvenir a la necesidad grave de la república. (Suárez, 1856, XII, trat. 3, disp. 7, sec. 4, 686).

Vemos que Suárez antepone no sólo las propiedades de los ciudadanos al bien común de la república, además el individuo debería perder su vida en su

5 Un análisis completo sobre la cuestión fiscal en Francisco Suárez se puede encontrar en Hernandez Fradejas (2017: 283-295) 
favor. Sin embargo, Suárez, al igual que la mayor parte de los escolásticos, no concreta la actuación del Estado dejando un margen de intervención pública bastante difuso. Aún así, como acabamos de ver, el bien común de la república está por encima incluso del derecho a la vida (aunque antes dijimos que existía una primacía de vida sobre la propiedad de los individuos en el supuesto de extrema necesidad). De ser así estaríamos contemplando la siguiente prelación: primero, el bien común de la república; en segundo lugar, la vida de los súbditos y, para terminar, propiedades de los individuos. Una jerarquía bien distinta a la que encontramos en la obra de John Locke en donde aparece en primer lugar la vida, en segundo las propiedades y en tercer lugar el Estado que ha de velar por las dos primeras. Éste aspecto merecería un estudio por parte de la teoría política porque ni tan siquiera Thomas Hobbes mantuvo ideas similares a la del autor escolástico.

Esta relación existente entre bien común en la escolástica ha sido estudiada por Schumpeter. Según este autor los doctores escolásticos emplearon un «concepto axial» de Bien Público por lo cual comparten con la moderna Welfare Economics un carácter eminentemente utilitarista (Schumpeter, 1994:136). En lo que nos atañe, la teoría de la propiedad es uno de estos casos donde aparece el concepto de Bien Público, transformado por la terminología escolástica en «Bien Común». Como hemos visto, la utilidad social justifica la aparición de la propiedad privada en las sociedades civilizadas; pero Vitoria, Suárez o Molina también admiten que por el Bien Común el soberano pueda revocarla. Schumpeter interpreta quizá algo radicalmente esta actitud en su estudio sobre la escolástica. Las consideraciones de utilidad social — dice- «hablaban en favor de la propiedad privada; pero no había principio teórico ni moral que les impidiera [a los escolásticos] llegar al resultado contrario si los hechos se lo sugerían» (Ibíd.: 135). Sin llegar tan lejos como Schumpeter, es probable que los escolásticos emplearan un doble criterio utilitarista en su teoría de la propiedad que en cierta forma nos recuerda de nuevo la tesis de Thomas Horne. Según este autor, no existe una ruptura conceptual entre la defensa de una teoría de derechos exclusivos de los siglos XVII, XVIII y XIX, donde se sentaron las bases de la tradición liberal, y las políticas redistributivas e intervencionistas del siglo XX (Horne, 1990). Lo mismo se podría decir sobre la teoría de la propiedad en el pensamiento escolástico. A lo largo de las obras de estos teólogos cohabitan dos nociones de derecho: un derecho de propiedad exclusivo y otro inclusivo. Es decir, defienden por un lado la propiedad privada pero, por otro, admiten la posibilidad de abrogación bien en caso de necesidad — como vimos anteriormente-, bien cuando el soberano lo considerase beneficioso para la comunidad.

\section{Conclusiones}

A lo largo de las páginas precedentes se ha intentado exponer la doctrina de la propiedad de Francisco Suárez. Para hacer una valoración de cada uno de los aspectos tratados — justificación de la propiedad privada, categoría 
jurídica, justificación moral de la apropiación y los límites morales y civiles de ésta- se ha contextualizado las ideas de Suárez con la tradición escolástica precedente. De esta manera pensamos que podríamos hacer un mejor balance de las novedades de su teoría.

De todo lo anterior podemos decir que la doctrina de Suárez, en su mayor parte, tiene los mismos atributos que encontramos en la Escolástica Española, es decir, se puede decir que, como Vitoria, Soto o Molina, la doctrina canónica sobre la propiedad se amolda a las circunstancias económicas del momento y, por tanto, flexibiliza enormemente los límites de la propiedad y las obligaciones del propietario. Un caso particular en este sentido lo podemos encontrar en la obligación de dar limosna de lo superfluo que Suárez amplía hasta casi dejar vacío de contenido este precepto. Aún así, no abandona la senda escolástica y mantiene los mismos postulados que aparecen en la tradición aristotéico-tomista como la defensa consecuencialista de la propiedad o el límite a la exclusividad en caso de extrema necesidad. Sin embargo, no continúa esta senda cuando analiza la categoría de la apropiación como un derecho permisivo y preceptivo al mismo tiempo, un atributo que confiere la exclusividad al propietario y dota a sus ideas de una gran modernidad. Ahora bien, si debemos destacar un aspecto realmente significativo en su teoría, éste lo encontramos en la justificación de la apropiación en el estado de naturaleza: un aspecto muy relevante porque se asemeja al que iba a mantener más tarde John Locke en el Segundo Tratado sobre el Gobierno Civil. No obstante, aunque son evidentes las similitudes de ambos autores en este campo, no por ello deberíamos admitir que en Suárez está la semilla del liberalismo político lockeano. Las competencias que otorga al Estado sobre las propiedades de sus súbditos arroja dudas a este respecto y merece un estudio mayor que excede el objetivo de este trabajo.

\section{BiBLIOGRAFÍA}

Baciero Ruiz, F. (2012). «El concepto de derecho subjetivo y el derecho a la propiedad privada en Suárez y Locke». Anuario filosófico, 45(2), pp. 391-42.

Ferreiro López, A. (1948). «La naturaleza de la propiedad privada en las doctrinas de Suárez», Pensamiento Vol. 4, núm. extraordinario, pp. 449-492.

Hernández Fradejas, F. (2017). «Derecho de propiedad privada y fiscalidad en Francisco Suárez», Anuario Filosófico, 50(2), pp. 269-296.

Horne, T. A. (1990). Property Right and Property. Political Argument in Britain, 16051834. Chapel Hill and London: The University of North Carolina Press.

Locke, J. (1990). Segundo Tratado sobre el Gobierno Civil [1690]. Madrid: Alianza Editorial.

San Emeterio, N. (2005). El concepto de propiedad en la Edad Moderna. Madrid: Tecnos. Schumpeter, J. A. (1994). Historia del Análisis Económico. Barcelona: Ariel.

Sierra Bravo, R. (1975). El pensamiento social y económico de la escolástica. 2 Volúmenes. Madrid: Consejo Superior de Investigaciones Científicas, Instituto de Sociología Balmes. 
Soto, Domingo de (1968). De la Justicia y del Derecho (De Iustitia et Iure). Madrid: Instituto de Estudios Políticos.

Suárez, F. (1856). Opera Omnia, A.D.M. André De., París.

Suárez, F. (1967). Las Leyes (De Legibus ac Deo legislatore). Madrid: Instituto de Estudios Políticos.

Tomás de Aquino (1963). Summa Theologica. Vol. II Prima Secundae; Vol III: Secunda Secundae. Madrid: BAC.

Universidad Rey Juan Carlos

Nieves San Emeterio

Facultad de CC. Jurídicas y Sociales

nieves.sanemeterio@urjc.es

[Artículo aprobado para publicación en enero de 2018] 